\title{
The Development and Implementation of the Online Course "IT Interaction in the Digital Economy"
}

\author{
Pankratova O.P. ${ }^{1,2, *}$, Abdullaev J.A. ${ }^{2}$, Konopko E.A. ${ }^{1}$
}

\author{
${ }^{1}$ North Caucasus Federal University, Stavropol, 355017, Russia \\ ${ }^{2}$ Chechen State Pedagogical University, Grozny, Chechen Republic, 364031, Russia \\ * Corresponding author. Email:olga.informat@gmail.com
}

\begin{abstract}
The process of universal digitalization inevitably changes the structure of employment of the population. Knowledge and skills in the information technology field are necessary for successful lives and careers in the digital society. In the article need of forming of digital skills is proved, the program of the online course "IT Interaction in the digital economy" and the description of the organization of online training of the general population in digital technologies and opportunities of their application in professional activity and everyday life are provided. The activity of the teacher in the organization of online training is investigated. Recommendations about the preparation of the remote content of the course, the choice of technologies and methods of training are made. Interactive methods in online training are based on the collaboration of trainees, the exchange of knowledge, interaction of listeners and teachers. Video lectures, virtual seminars, discussions at the forum, online consultation trained, etc. belong to forms of the organization of online training. The new role of the teacher: coordinating of cognitive process, manual of educational projects with the help of network technologies, effective maintenance of training. The maintenance of the online course is constructed on the analysis of the changes happening in society and Russian education in the conditions of digitalization of the national economy. Implementation of the online course promotes the solution to the problem of professional development and training of the new generation, the professionals who are effectively meeting the requirements of modern digital society ready to adapt to the changes happening in it. Keywords: online training, digitalization, online course, information technology interaction, interactive
\end{abstract}

technologies and teaching methods, ongoing education

\section{INTRODUCTION}

Digitalization, i.e. transfer of all types of information in the digital format, gets absolutely into all fields of activity. Not only approaches in the field of production management, services, and the enterprises, but also the organization of everyday life of the population change. It is more and more digitized data, the computer equipment is constantly improved and becomes more complicated, the Internet becomes universal, and technologies of digitalization are implemented into all new areas of human activity. Digitalization of the economy leads to the penetration of technologies not only into the working environment but also into the personal space of each person.

The process of universal automation and digitalization inevitably changes the structure of employment of the population and the educational environment. The analytical skills, knowledge, and skills helping to live in the world rich with information and communication technologies including basic skills of search and information processing, ability to master new technologies and to work with them are necessary for successful career and life in the digital society. Probably, we do not completely understand what it means to live in the digital world. Most likely, we will be taught it by "digital generation" (digital natives [1]) - those who were born and will live in "the world of the digit". Promptly developing digital economy implemented to all spheres of life activity in modern society generates need not only for system technology breaks but also for review of training to professional activity.

It is already proved that necessary professional skills can be developed throughout all work of the person. These skills depend on the accomplishment of a certain type of activity, on objectives is precisely set conditions, on specifics of work and the executed operations at the specific enterprise. The main task of the educational organizations performing vocational training to develop the basic skills which are not depending on the sphere of employment and necessary for all working citizens and also to create the general professional abilities oriented to the selected profession. In the conditions of digitalization of society and production to discharge of necessary basic skills, i.e. skills necessary for all irrespective of the profession, skills of work with digital information, or 
digital skills belong. Digital skills allow people to create and exchange digital content, organize communication and to solve problems for effective and creative self-realization in training, work, social activity and life in general [2]. For the solution of the objective - forming of digital skills - the educational organizations include the different courses connected with the mastering of digital technologies in programs of preparation.

However, not only yesterday's graduates of the educational organizations but also everyone living and working in the digital society, in the independence of age, shall possess digital literacy which cornerstone digital competence is. We will understand as digital competence "capability solve various problems in the field of use of information communication technologies: use and create content utilizing digital technologies, including search and information exchange, answers to questions, interaction with other people and computer programming" [2].

Thus, the growing requirement of the development of digital skills of the population, the need for the application of digital technologies for professional activity, for training and everyday life, initiated the development of the online course "Information and Technology Interaction in the conditions of Digital Economy".

\section{MATERIALS AND METHODS}

The course is developed and approved during the implementation of the federal draft "New Opportunities for Everyone" of the national Education project [3]. The program of the course is directed to the professional development of the working citizens within the preparation of personnel potential for the digital economy, and also to the mastering of digital technologies by the general population, including citizens of retirement and preretirement age for their adaptation in the digital society. The course was implemented in the online training format. Remote content of the course was provided to listeners in the learning management system of the North Caucasian Federal University (NCFU) - https://el.ncfu.ru/.

Form of education in the online mode acquired special relevance at the present stage that is caused by the active implementation of online courses in the world education system, and also opportunities for application of technologies online for implementation of the concept of training at the extent of all life. The need to increase in the availability of education for all and implementation of the concept of continuous education due to the development of the Russian digital educational space is stated in the priority project for 2016-2021. "Modern digital educational medium in the Russian Federation" [4]. Thus, online education is demanded in society, actively develops and progresses the educational organizations, and also is the priority of the state policy of Russia aiming at an increase in the presence in the world market of educational services.

Online courses become more and more popular and demanded education. It is connected first of all with the fact that they allow solving problems of additional vocational training and retraining at the expense of the possibility of creation of the individual educational trajectory of trained. Besides, online courses create the capability to self-organization and self-education that is the necessary condition for implementation of the concept of continuous training.

Online training is the method of the organization of the process of independent studying of training materials with the use of the educational environment based on Internet technologies, training utilizing the Internet and multimedia [5].

In didactics, online courses define as the form or the type of training. In practice, online courses are implemented in the format of electronic or remote learning. However, it is necessary to notice that not all electronic and remote courses are conducted online. We determined the online course as the special type of the e-learning realized on the remote platform, containing all necessary set of the educational and methodical materials allowing to create at trained the competences determined by the program at the expense of the possibility of immersion on educational Wednesday for studying of theoretical materials of the course (utilizing video of lectures or in forward translation), accomplishment of tasks and file exchange with the tutor, passings of interactive tests, communication with teachers and fellow students. Thus, the main difference of online courses from remote is the implementation of communication in training activity and effective back coupling with the teacher during the entire period of training [6].

The educational program of the online course "Information and Technology Interaction in the conditions of Digital Economy" is developed according to requirements of the professional standards "The Consultant in the Field of Development of Digital Literacy of the Population (the Digital Curator)", "Additional Education Teacher of Children and Adults", "Manager of Projects of Information Technology Field".

The mission of the online course - to promote the forming of the new generation of professionals for digital economy who are effectively meeting the requirements of modern digital society ready to adapt to the changes happening in it.

The purpose of the online course consists of forming and development of information and technology competence of the population, in the transfer of special and fundamental knowledge in the field of digital technologies, in training of the professionals knowing ideology of digital society and possessing readiness for implementation of professional activity in it.

Result of implementation of the program of the course is readiness of listeners for application of digital technologies in professional activity and everyday life, and also readiness for implementation of the new type of activity: the consultant in the field of development of digital literacy of the population (the digital curator) to train capability in digital technologies the general population. Forming of the necessary professional competences which are trained is performed utilizing the developed methodical providing the online course, based on the complexity of 
modern methods of training and application of special education and information technologies including elearning [7] technologies.

The productivity of online training is reached utilizing active and interactive technologies and methods of training. The active methods of training applied at the implementation of the online course are directed to the accomplishment of various creative tasks, the solution of problem situations and search of the necessary information. Training of listeners is followed by support and control from the teacher-tutor, employing a dialog of the listener and the teacher in the online mode. Interactive methods, at the decision, but it is aware of tasks, are based on the collaboration of listeners, the exchange of knowledge, interaction of listeners and teachers [5, 8]. For the implementation of the program of the course application of such interactive methods of training as discussion, educational pieces of training, the solution of practical tasks, project activity, the case technology, game technologies, and others is provided. In the course of online training virtual seminars in the forum format, online consultation trained and estimation of results of their work on the platform of remote learning were organized [9]. All these methods are actual and quite are suitable for application in the system of online training.

The packet of methodical materials including is developed for implementation of the contents of the online course: author's lectures and presentation materials, video lectures, tasks for practical accomplishment and methodical recommendations to them, cases (for the analysis and the solution of practical situations), estimated materials of different types (computer tests, questionnaires, creative and detailed designs, etc.). As additional materials, it is aware references to actual third-party resources are used.

Educational and methodical materials of lecture and practical works were available to listeners in the system of the organization of training of SKFU LMS Moodle the entire period of training. Also, the possibility of their downloading by listeners for further use in professional activity and everyday life was provided.

The educational and methodical complex of the online course on modules is provided by the following subjects: Introduction to the profession of the digital curator, Electronic services of digital society, Technologies of the organization of personal digital space, Legal bases of digital society, Information security in digital space, Bases of use of IT technologies in digital society, Technologies of application of IT for the organization of communication, Technologies of application of IT in everyday life, Hardware and technical providing personal digital space, Mobile devices in digital space.

The maintenance of the online course and the applied methods, technologies and forms of work allowed listeners of the program to receive:

knowledge:

- about the digital medium and digital competences, components of digital literacy;

- about the state policy in the field of digitalization of education, economy, and society;
- about features of the development of electronic services in the digital society and digital platforms of the state services;

- about the rights of citizens in the digital society and the legislation in the field of information technologies;

- about safety bases on the Internet;

- about standards of ensuring the availability of services, tools, and methods of increase of availability of services;

- about hardware and technical providing personal digital space of citizens;

- skills:

- organizations of personal digital space and rendering services to the population in the organization of personal digital space;

- receipts of the state services in the system of the electronic government;

- works in legal-reference systems;

- safe net surfing Internet and information security support;

- applications of programs of office packets for the solution of daily tasks (creation of text documents, use of opportunities of electronic spreadsheets for conducting cost accountings, etc.);

- applications of the IT technologies for the organization of communication and in everyday life of citizens (technology of work on the websites with entertaining content, news portals, webinar platforms, educational portals, etc. Technologies of purchases through Online stores);

- connections, setup and operation of peripheral devices PCs, and also skills on the setup of mobile devices.

The preparation of educational content for the online course demands the application of a special approach to its development. For example, theoretical materials of the course can be presented in the form of the electronic version of the textbook or manual which is followed by interactive presentations and video lectures. And the presentations shall not repeat the text of the manual completely. The presentation - it is the evident submission of the stated text in the form of schemes, charts, drawings, tables. The obligatory element of the online course is video lecture or lecture in real-time (such lectures it is accepted to call webinars). Video lectures are the training aid which uses in the online course that allows organizing the multitouch educational environment for effective assimilation of educational information. However, when viewing video lectures, trainees have no opportunity to ask questions to the teacher in the online mode. Absolutely another is the lecture in the webinar format. The webinar is the kind of web conference, holding online meetings or presentations via the Internet. The webinars held within the online course allow organizing discussion of the studied questions in real-time. Thus, using webinars in online training, it is possible to organize not only lectures but also to hold virtual seminars.

Online training is the generally independent work of trainees controlled and directed by the teacher [10]. The volume of tasks and the estimated time allowed for their accomplishment shall be comparable to the program of the course. The teacher developing online course content shall 
represent accurately what is the time can it is required to the listener for the accomplishment of this or that task and not to overload listeners. Each performed task shall be checked. The listener shall receive the assessment, it is desirable with the comment of the teacher.

In online training forming of the system of motivation trained is important. Criteria for the assessment of the activity of listeners shall be accurately formulated and registered. For each type of activity trained to get a certain number of points. Listeners shall foreknow in what volume to them it is necessary to perform tasks and how many points they, as a result, need to gather for successful certification at the rate of.

The organization online training demands a change of approaches to the organization of the educational process and forming of new competencies of the modern teacher. From the teacher, it is required not just to seize new educational technologies, but also to change the teaching technique radically. The teacher does not go to the audience to train. It shall be able to manage the educational process at distance, using the communicative opportunities given in online training [11].

\section{RESULTS}

Implementation of the online course allowed to receive the following results:

- digital and information and technology competencies of listeners are created;

- listeners receive new skills, demanded and necessary for professional activity and life in digital educational space;

- degree of knowledge and digital literacy of the population is raised;

- skills of the organization of personal digital space of listeners are developed;

- listeners purchase skills of rendering advisory services to the population in the application of digital technologies, informing and maintenance of personal digital space.

As a result of the mastering of materials of the online course at listeners of the program competencies necessary for the implementation of professional activity in the conditions of the digital economy were created. Among the created competences it is possible to select:

- it is capable to project professional activity and the solution of daily tasks in the digital medium of modern society;

- it is capable to manage data, information and digital content, to make optimal managerial solutions taking into account opportunities of use of the available resources;

- it is capable to apply information technologies, different search engines mean communication and social services at the level of the advanced user and to carry out explanations on their application.

The created information and technology competencies of listeners can be applied by them to implementation new the type of activity - the consultant in the field of development of digital literacy of the population (the digital curator) that conforms to requirements of digital economy and promotes ensuring stability of citizens in information and telecommunication infrastructure of the Russian Federation.

300 listeners from different regions of the country took part in online training in Information and Technology Interaction in the conditions of the Digital Economy program.

The wide range of listeners aged from 25 to 50 years, and also working citizens of retirement and pre-retirement age (from 51 to 65 years) was covered. The percent of listeners of retirement and pre-retirement age made about $20 \%$ of the total quantity of listeners.

Following the results of online training, the complex assessment of the competences purchased by listeners is carried out. Level of the gained knowledge, skills were estimated on the final assessment in the form of testing of the acquired theoretical knowledge and practical skills of work. All listeners coped with the offered tasks. The majority of listeners showed a high level of mastering of materials of the course.

The assessment was "perfectly" received by $11 \%$ of listeners, it is "good" - 80,67\%, is "satisfactory" - 8,33\% of listeners.

The received results demonstrate that time volume allotted on the mastering of the program and its components, forms, and methods of work with listeners were selected truly and allowed to achieve the objectives of training and to receive the results declared in the program.

On completion of online training questioning of listeners which showed the following results was carried out:

Results of courses completely met expectations of $67 \%$ of listeners, it is rather "yes", than "no" - $24 \%$ of listeners, it is rather "no", than "yes" - 9\% of listeners.

Among the most useful studied on courses listeners specified by that: "Information security in digital space", "Electronic services of digital society", "Technologies of the organization of personal digital space"

Among subjects that would like to study in more detail listeners specified: "Mobile devices in digital space", "Technologies of application of IT in everyday life of citizens". The training, taking place in the mode of online courses, satisfied $61,6 \%$ of listeners, it is rather "yes" than "no" - 28,4\% of listeners, it is rather "no", than "yes" or are not satisfied $-10 \%$ of listeners.

From forms of work most of the listeners gave the preference to online training - $48,9 \%$, full-time courses $9,5 \%$, combined (online training is combined with resident instruction) - 41,6\%.

The vast majority of listeners were positive for the usefulness of the gained knowledge for practical work and everyday life: yes - 70,3\%, it is rather "yes", than "no" $29,7 \%$.

The question "Whether New Experience of Application of ICT in Professional Activity and Everyday Life in Digital Society Was Encouraged by You" was positively answered by $100 \%$ of listeners: yes $-74,3 \%$, it is rather "yes", than "no" - 25,7\%. 
and safety of information and telecommunication infrastructure of the Russian Federation at all levels of information space.

4. The teachers of higher education institution performing development of content of the online course and training of listeners purchased the skills of work in the mode of online training and competence allowing them to perform preparation not only students but also different segments of the population, including people of advanced age and disabled people to the digital technologies demanded for life and professional activity in real sector of economy of the territorial subject of the Russian Federation.

\section{SUMMARY}

In the Russian and foreign practice, autonomous courses on studying of information technologies are repeatedly offered, however, uniqueness and feature of the provided online course is that in its framework conditions for training and development of the personnel possessing professional information and technology competence, profound special and fundamental knowledge in the field of the digital technologies knowing ideology of digital society and possessing readiness for implementation of professional activity in it will be created.

The new online course will be actual for society many years, will promote the solution of the problem of training in the region, to satisfaction of requests of digital society and increase of information literacy of the population.

\section{REFERENCES}

[1] Prensky, Marc. "Digital natives, digital immigrants part 1" On the horizon 9, no. 5 (2001): 1-6.

[2] Training in digital skills: global challenges and advanced practicians. The analytical report to the III International conference "Is more than training: how to develop digital skills", Corporate University of Sberbank. - M.: Autonomous Non-Commercial Organization of DPO "Sberbank Corporate University", $2018-122 \mathrm{p}$.

[3] Passport of the federal draft "New Opportunities for Everyone" of the national Education project of DOI: https://minobraz.kamgov.ru/files/5cd23c0d826352.4752 4425.pdf

[4] Passport of the priority project "Modern Digital Educational Medium in the Russian Federation". DOI: http://www.consultant.ru/document/cons_doc_LAW_2 16432.

[5] Fomina A.S. Online training in the higher educational institution: techniques, content, technologies. DOI: https://clck.ru/M8kyR 
[6] What online training differs from remote learning in. DOI: https://clck.ru/FMbf3

[7] O. Pankratova, E. Konopko, O. Mezentseva, R. Nemkov. The Preparation of a Modern Computer Science Teacher with the Help of Resource-Saving Technologies and Green IT Implementation. Proceedings of the 2018 multidisciplinary symposium on computer science and ICT. Stavropol, Russia, October 15, 2018. DOI: http://ceur-ws.org/Vol2254/10000222.pdf.

[8] S. Zenkina, T. Suvorova, O. Pankratova, L. Filimanyuk. The Method of Design of Electronic Advanced Training Courses for the Development of Information Competence of the Teacher. Proceedings of SLET-2019 - International Scientific Conference Innovative Approaches to the Application of Digital Technologies in Education and Research, Stavropol Dombay, Russia, 20-23 May 2019. pp. 366 - 375. DOI: http://ceur-ws.org/Vol-2494/paper_35.pdf.

[9] S. Zenkina, O. Pankratova, E. Konopko, A. Ardeev. Model of Organization of Network Project-Research Students Activities in Collaboration with City-Forming Enterprises. Proceedings of the 2018 multidisciplinary symposium on computer science and ICT. Stavropol, Russia, October 15, 2018. DOI: http://ceur-ws.org/Vol2254/10000290.pdf

[10] Y. Bogatyreva, A. Privalov, V. Romanov, E. Konopko. The Organization of Scientific Research Work of Students in the Conditions of the Digital Environment in the Modern Universities. Proceedings of SLET-2019 - International Scientific Conference Innovative Approaches to the Application of Digital Technologies in Education and Research, Stavropol Dombay, Russia, 20-23 May 2019. pp. 95-103. DOI: http://ceur-ws.org/Vol-2494/paper_7.pdf.

[11] E. Konopko, O. Pankratova, E. Nersesyan, J. Abdullaev. Training of Teachers for Professional Activity in the Digital Environment of the Educational Space. Proceedings of SLET-2019 - International Scientific Conference Innovative Approaches to the Application of Digital Technologies in Education and Research, Stavropol - Dombay, Russia, 20-23 May 2019, pp. 205-212. DOI: http://ceur-ws.org/Vol2494/paper_18.pdf. 